YAK 378

ББК 74.58

DOI 10.22394/1682-2358-2020-1-83-90

V.A. Shatsyllo, senior lecturer of the Sociology and Social Policy Department, Povolzhsky Institute of Management named after P.A. Stolypin, Branch of the Russian Presidential Academy of National Economy and Public Administration

\section{IMAGE \\ OF EDUCATIONAL ORGANIZATION \\ IN THE PROCESS OF PROFESSIONAL SELF-DETERMINATION OF YOUTH (Case Study of the Saratov Region)}

The problems in the sphere of professional self-determination of modern youth are analyzed. The role of image of higher educational institutions as one of the factors of professional self-determination is revealed. The components of the image of educational organizations and their influence on the choice of higher education institution and profession are considered. The concepts of "image" and "branding"are compared in the context of their formation within the framework of higher education institutions of the Saratov region.

Key words and word-combinations: professional self-determination, image, branding, higher education, educational organizations.
B.A. Шацилло, старший преподаватель кафедрь сочиологии и сочиальной политики Поволжского института упраљления имени П.А. Стольтина - филиала Российской академии народного хозяйства и государственной службь при Президенте РФ (email: shacillo93@mail.ru)

\section{ИМИАЖ \\ ОБРАЗОВАТЕ АЬНОЙ \\ ОРГАНИЗАЦИИ В ПРОЦЕССЕ ПРОФЕССИОНААЬНОГО \\ САМООПРЕАЕАЕНИЯ \\ МОАОАЕЖКИ \\ (на примере \\ Саратовской обкасти)}

Аннотац̧ия. Анализируются проблемы в сфере профессионального самоопределения современной молодежи. Выявляется роль имиджа высших учебных заведений как одного из факторов профессионального самоопределения. Рассматриваются составляющие имиджа образовательных организаций и их влияние на выбор вуза и профессии. Сравниваются понятия «имидж» и «брендинг» в контексте их формирования в рамках деятельности высших учебных заведений Саратовской области.

Ключевые слова и словосочетания: профессиональное самоопределение, имидж, брендинг, высшее образование, образовательные организации.

B продуктивности профессионацьного становмения мичности явцяется способность на- 
ходить Аичностный смысл в профессиональной деятельности, самостоятельно проектировать и выстраивать свою карьеру, ответственно принимать решения о выборе профессии, специальности и места работы.

Подобные проблемы возникают переА человеком в течение всей жизни, но особенно актуальными они становятся для молодежи. Молодые Аюди быстро изменяются и развиваются, следовательно, на разных временных стадиях одни и те же задачи профессионального самоопределения требуют разцичных решений. Постоянное уточнение своего места в мире профессий (Аибо конкретной профессии), осмысление соџиально-профессиональной роли, отношения к труду, комлективу и самому себе становятся важными компонентами жизни человека. ИногАа возникает отчуждение от профессии, человек начинает ею тяготиться, испытывает неудовлетворенность профессиональным положением. Нередки случаи вынужденной смены профессии (специальности) и места работы. Подобные проблемы связаны с трудностями профессионального самоопределения и слабым качеством профориентационной работы.

Опыт работы в вузе показывает, что абитуриенты даже в период приемной кампании не могут определиться, на какую специальность или направление подготовки им цемесообразно поступать. Этому способствуют и федеральные нормы, предоставцяющие абитуриентам право подавать заявления в пять вузов по трем разным специальностям или направлениям подготовки. Таким образом, переА молодыми мюдьми возникает нелегкий выбор вуза и направления подготовки или специальности. При наличии в разцичных высших учебных заведениях схожих образовательных программ конкуренџия на рынке образовательных услуг возрастает, что непосредственно отражается на проџессе профессионального самоопределения моАОАЫХ АюАей.

На наш взгляА, Амя успешного профессионамьного самоопредемения мюбой молодой человек должен обладать совокупностью знаний о каждой интересующей его сфере профессиональной деятельности. Все спещиальности и направмения подготовки представмяется необходимым анализировать с различных точек зрения:

- социально-экономической (общественная значимость, перспективность и возможность карьерного роста);

- производственно-технической (условия работы, характер нервно-психической напряженности, продолжительность рабочего дня и отпуска);

- производственно-педагогической (возможность поступления, условия и сроки обучения, тип учебного заведения, популярность вуза и образовательной программы);

- социально-психологической (требования к узкоспециальным, нравственным и организационным качествам) [1] .

В контексте Аанного исследования попытаемся изучить производственно-педагогический фактор профессионального самоопредемения современной молодежи, который вкмючает в себя представления абитуриентов, их родителей, педагогов и обшества в целом об имиАже той или иной обра- 
зовательной организаџии. Ведущая роль этого фактора стала очевидна при поступлении в высшие учебные заведения молодых мюдей, родившихся в период масштабного спада рождаемости в стране, когда вузы были вынуждены вести конкурентную борьбу практически за каждого абитуриента. В результате влияния демографических особенностей большинство образовательных организаций стали работать наА формированием положительного имиджа вуза в цемом и конкретных направлений подготовки и специальностей в частности.

Зарубежные исследования факторов выбора высшего учебного заведения свидетельствуют о том, что основным мотивом является академическая репутация вуза, которая формируется на основе создания определенного положительного имиджа образовательной организации, а также местоположения в различных рейтингах. Существенными факторами явмяются также местопоможение учебного заведения, наличие общежития дмя размещения иногородних студентов, возможность успешного трудоустройства и уровень образовательных программ, их востребованность и перспективность в условиях современного рынка труда [2] .

Отечественные исследования мотивов выбора высшего учебного заведения существенно не отличаются от зарубежных в контексте таких попумярных факторов, как имидж вуза и возможность Аальнейшего трудоустройства, но имеют ряд характерных особенностей, к которым относятся статус вуза (государственный или коммерческий), перечень дополнительных вступительных испытаний, кроме ЕГЭ, а также наличие военной кафесры [3].

В широком смысле имидж образовательной организации понимается как особенности, которые непосредственным образом характеризуют и идентифиџируют учебное заведение, а также выражаются в опредеменных формах и символах информации [4]. Подобные формы и символы создаются целенаправленно и в различных аспектах доносятся до целевой аудитории - абитуриентов, учителей, родителей, работодателей, партнеров, среАств массовой информации, органов власти и коммерческих организаџий. В структуре имиАжа образовательной организации традиционно выдемяют несколько составцяющих: визуальный и соџиальный имиАж вуза, имидж предоставления образовательных услуг, а также имидж студентов, профессорско-преподавательского состава и выпускников [5] .

На примере высших учебных заведений г. Саратова рассмотрим некоторые составляющие имиджа образовательных организаций. Визуальная имиджевая атрибутика мюбого учреждения, бесспорно, играет одну из первостепенных ромей в позиџионировании организации [6]. Визуамьный имидж высшего учебного заведения в первую очередь ассоџиируется с фирменным стилем вуза, цоготипом, фирменными цветами, ощушением от восприятия интерьера и оформления внешнего пространства вуза. Не скучайно каждое учреждение, в том числе и образовательное, имеет свой фмаг, герб, фирменную символику, слоган, моготип. К примеру, Саратовский соџиально-экономический институт РЭУ имени Г.В. Пмеханова в последние годы активно 
использует слоган «Все грани высшего», который хорошо запоминается и позитивно воспринимается целевой аудиторией. С оАной стороны, подобный мозунг указывает на широкий выбор образовательных программ Амя будущих абитуриентов (бакамавриат и спеџиалитет), а с Аругой - на возможность продолжения обучения по программам магистратуры и аспирантуры, перспективу развития и широкий спектр других возможностей дмя студентов. ВАияние визуацьных атрибутов на этапе знакомства абитуриентов, родитемей, партнеров с высшим учебным заведением, на наш взгляА, играет первостепенную роль с точки зрения психологии и маркетинговых технологий, поскольку позитивное впечатление от визуацьной составцяющей побужАает к заинтересованности остацьными аспектами деятельности образовательной организации.

В соответствии с современными трендами к общепринятым визуальным составцяющим имиджа вуза прибавилась характерная дия современного общества особенность, связанная сформированием контента Аля попумярных социальных сетей (Вконтакте, Instagram, Facebook) и активной работой с сайтом образовательной организации.

Соџиальный имидж вуза понимается как общественная, экономическая или культурная миссия образовательной организации, так как на современном этапе развития государства и общества необходимо готовить не только квацифицированных специацистов в той или иной сфере, но и граждан с высоким уровнем соџиальной ответственности [7]. Например, Саратовский государственный медиџинский университет имени В.И. Разумовского в рамках ПоАГОтовки студентов-меАИков веАет активную работу в сфере волонтерской и добровольческой Аеятельности, занимается пропагандой донорства крови на территории области, привлекая студентов Аругих вузов. Ежемесячно происходят выезды в отдаленные районы области с целью беспиатных профимактических осмотров граждан, а также информирования о симптоматике опасных болезней и необходимости обращения в меАиџинские учрежжения с целью их профицактики. В этой Аеятельности принимают участие не только студенты, но ипрофессорско-преподавательский, и руководящий состав университета.

Имидж образовательной услуги вкцючает в себя уникальность получаемого образования, престиж профессии, возможность успешного трудоустройства, стоимость обучения, особенности образовательной среды, соџиальную защищенность студентов вуза, материальную и техническую базу образовательной организации. Абитуриенты и их родители могут ознакомиться с Аанной составцяющей имиджа вуза переА поступлением благодаря проведению Аней открытых Аверей в новом формате, когда каждая образовательная программа подробно и в доступной форме презентуется преподаватемями, студентами и выпускниками специальности или направления подготовки. Так, масштабные мероприятия в рамках Аня открытых дверей в Поволжском институте управмения имени П.А. Столыпина - филиале РАНХиГС ежкегодно посещают окомо тысячи абитуриентов и их родителей. Мероприятие охватывает не толыко знакомство с инфраструктурой, общение с руководством вуза, студентами, 
преподавателями и сотрудниками отдела по работе с абитуриентами, но и возможность получить поАробную информацию об интересующей спещиальности или направлении подготовки. Основной упор декается на позиционирование уникальной образовательной услуги, поэтому каждое направление подготовки или спещиальность приходят к необходимости формирования собственного бренда.

Имидж профессорско-преподавательского состава включает не только уровень профессиональной компетентности, достижения и общий культурный уровень, но и внешний облик, а также соџиально-демографические характеристики. В настоящее время определенным трендом в сфере высшего образования явмяется участие в образовательном проџессе преподавателей-практиков, которые имеют возможность поделиться со студентами мичным профессиональным опытом, рассказать о современных тенденциях в рамках профессиональной сферы. Позитивным показателем является также способность преподавателя осуществлять комплексный, творческий подход к преподаваемым дисџиплинам, умение заинтересовать и привлечь студентов к разцичным видам деятельности во время внеаудиторных занятий.

Имидж студента- это жизненные и профессиональные приоритеты и ценности обучающихся, формы проведения досуга и стиль жизни в целом. В Саратовской области данные тенденџии отчетливо прослеживаются в рамках взаимодействия студентов раздичных вузов на совместных мероприятиях и площадках. К примеру, в рамках реализации проекта «Малая академия государственного управления» уже на этапе отбора кандидатов на обучение явно видны различия межАу представителями различных высших учебных заведений. Это выражается в качестве базовой подготовки студентов, манере их поведения и позиџионирования себя; существенное влияние оказывают корпоративные нормы, правила и ценности каждого из образовательных учреждений.

Имидж выпускника представляет собой модель будущего, которая формируется в сознании абитуриентов и их родителей на этапе выбора высшего учебного заведения. Существенное внимание этому компоненту удемяется со стороны органов власти. Так, в рамках подготовки областного мероприятия дця выпускников «Роза ветров» каждому высшему учебному заведению Саратовской области необходимо было преАставить видеоролик с профессиональной историей успешного выпускника, который транслировался во время проведения мероприятия с целью информирования цемевой аудитории о возможностях и перспективах выпускников каждой образовательной организации области. В свою очередь, высшие учебные заведения ежегодно проводят мониторинги трудоустройства выпускников, веАут статистику, которая активно используется в период приемной кампании.

Очевидной представмяется необходимость формирования позитивного имиджа с использованием инструментов маркетинга. Чаще всего дмя этого применяется брендинг - маркетинговый процесс по формированию и про- 
Авижению определенного продукта или услуги. Определение брендинга в контексте высшего образования трактуется как целенаправленный проџесс управления, формирующий ряд материальных и нематериальных особенностей, которые позвоцяют разцичным образовательным организациям позиционировать себя с точки зрения определенной уникальности в сравнении с Аругими организациями [8].

Сложность позиционирования образовательного бренда как части формирования имиджа высшего учебного заведения состоит в том, что позиционирование происходит в двух направлениях: на рынке образовательных услуг и рынке труда. С одной стороны, необходима популяризация определенных образовательных программ, а с Аругой - продвижение выпускников на рынке труАа.

Сегодня к основным атрибутам бренда образовательной организации слеАует отнести историю учебного заведения, так как вузы с богатой историей и традиџиями пользуются большим доверием со стороны абитуриентов и их родителей. ОАним из веАущих вузов области считается Саратовский госуАарственный национальный исследовательский университет имени Н.Г. Чернышевского, основанный в 1909 г. В общественном сознании присутствует распространенный стереотип: чем дольше существует вуз, тем он надежнее, а образование качественнее и фундаментальнее. Также важную роль играет территориальное расположение вуза. Саратов заслуженно носит статус стуАенческого города, что влияет на поток абитуриентов из других регионов и зарубежных стран. Это обусловлено тем, что молодые цюАи имеют возможность подать Аокументы в несколько высших учебных заведений в одном городе. Естественно, города, где есть только одно высшее учебное заведение, существенно уступают по этому параметру.

Значительное влияние на имидж вуза оказывают его сотрудники, в частности профессорско-преподаватецьский состав, а также студенты. В современной образовательной среде приветствуется развитие и продвижение преподавателями мичностного бренда, чему способствует выход за рамки классического преподавания, вовлеченность в разцичные проекты, экспертная деятельность в определенной сфере, ведение персональных блогов и страниц в соџиальных сетях. Аля современных студентов важно, чтобы преподаватель не только давал качественные знания, но и в определенной степени выступац наставником в сфере профессионацьной социализации и научной деятельности. Такой тип взаимодействия студентов и преподавателей выгоден не только обучающимся, но и преподавателям, так как большая часть достижений, составляющих мичный бренд преподавате я - это успехи его студентов в различных сферах: профессиональных олимпиадах, научнопрактических конференциях, молодежных форумах и грантовых конкурсах. Аанное мнение также подтверждается тем, что многие вузы в рамках аттестации профессорско-преподавательского состава учитывают комплексную оџенку преподавателя со стороны студентов, которая характеризует не только качество преподавания, но и манеру общения, объективность и Аругие мичностные качества преподавателя [9] . 
Определенный вклад в развитие бренда и повышение имиджа вуза вносят известность, открытость и интегрированность учебного заведения во внешнюю среду. Эти показатели выражаются в положении того или иного высшего учебного заведения в национальных и глобальных рейтингах, которые формируются с определенной периодичностью и публикуются в средствах массовой информации с цемью информирования заинтересованных во взаимодействии и сотрудничестве с вузом сторон. Информационная открытость проявцяется в активном взаимодействии высшего учебного заведения со средствами массовой информации. Помимо публикаций основных новостей, событий и Аостижений на собственном сайте и соџиальных сетях, ведется активная работа по продвижению в городских, областных, краевых, национальных и международных источниках [10].

С нашей точки зрения, понятия «имидж» и «брендинг» и их составияющие имеют сходство, но в контексте образовательных организаций их необходимо четко разграничивать. Так, формирование симьного и успешного бренда вуза должно быть направлено на создание долгосрочных партнерских отношений с органами власти, представителями бизнеса, Аругими образовательными организаџиями, позитивное взаимодействие со средствами массовой информаџии. Имидж вуза, в свою очередь, ориентирован на укрепление корпоративной культуры, активное взаимодействие с целевой аудиторией (абитуриенты и их родители, студенты, сотрудники и профессорско-препоАавательский состав), завоевание авторитета в научном и профессиональном сообществах.

Итак, в образовательных организаџиях наряду с основной функщией поАготовки высокопрофессиональных каАров Амя различных сфер деятельности и развития научного потенциала, идет непрерывная работа над созданием успешного бренда и формированием позитивного имиджа. В вузы с «громким именем», высоким положением в рейтингах и положительным имиджем поступают, как правимо, талантливые и перспективные абитуриенты, впоследствии становящиеся студентами, которые продоцжают проџесс формирования имиджа вуза, а затем профессионалами, подтверждающими компетентность руководителей вузов, профессионализм профессорско-преподавательского состава, позитивное влияние существующей корпоративной культуры и ценностей образовательной организации.

Большая часть Аюдей формируют отношение к размичным организащиям, в том числе и образовательным, с учетом совокупности кичного и группового опыта, меняющихся џенностных ориентаџий. Особенно актуально это Аля молодежи, с учетом их соџиально-демографического положения и возрастных особенностей. Формирование в сознании общественности положительного «образа» образовательного учреждения достигается посреАством целенаправленного проџесса работы наА всеми составляющими имиджа. Наиболее актуальным проџесс создания позитивного имиджа явмяется именно для высших учебных заведений, так как одним из кмючевых моментов в проџессе профессионального самоопределения современной молодежки является выбор вуза. В процессе выбора Аля абитуриентов и их 
родителей немаловажное значение имеют размичные составляющие имиАжа образовательной организации: история высшего учебного заведения, уникацьность образовательных услуг, качественная визуацьная составцяющая, образ студента, выпускника, представителей профессорско-преподавательского состава.

Сформированность имиджа высших учебных заведений вмияет на успешность процесса профессионального самоопределения современной молодежи, а также воздействует непосредственно на развитие системы образования в цемом. Основной результат подобной деятельности заключается в возможности подготовить современное общество и каждого человека к профессиональной Аеятельности в условиях высокого уровня конкуренции в контексте функционирования системы рыночной экономики.

\section{Библиографический список}

1. Володина К.А. Формирование образа профессии у студентов в рамках компетентностного подхода // Молодой ученый. 2014. № 14. С. 244-247.

2. Кондаков И.М., Сухарев А.В. Методологические основания зарубежных теорий профессионального развития // Вопросы психологии. 1989. № 1. С. 158-164.

3. Абдрахманова Л.В., Никонова Э.И. Основные факторы, влияющие на выбор вуза абитуриентом // Вестник экономики, права и социологии. 2017. № 3. С. 113-116.

4. Тринитатская О.Г., Бочаров С.В. Формирование позитивного имиджа образовательной организации в условиях конкурентной среды // Мир науки. Педагогика и психология. 2017. № 4. C. 54-61.

5. Фролова О.В. Имидж как условие конкурентоспособности вуза // Высшее образование в России. 2012. № 6. С. 121-126.

6. Яковлев Л.С., Рангелова Ц.Ф. Перспективы креативной рекламы в системе высшего образования (компаративный анализ на примере России и Болгарии) // Вестник Поволжского института управления. 2016. № 4 (55). С. 26-33.

7. Косарева O.E. Имидж вуза как элемент системы маркетинга образовательных услуг // Ученые записки Оренбургского государственного университета. Сер.: Гуманитарные и социальные науки. 2014. № 1. С. 63-67.

8. Спирина Н.А. Алгоритмизация процесса построения бренда высшего учебного заведения: методический аспект // Вопросы управления. 2016. № 2 (20). С. 261-267.

9. Рябкова В.А., Кузнецов К.С. Личный бренд преподавателя вуза как способ формирования наставничества в образовательных инновациях // Европейский и отечественный опыт инновационной культуры и отношений интеллектуальной собственности: коммуникативные аспекты: сборник материалов Всероссийской конференции с международным участием. Ижевск, 2019.

10. Примина О.М. Рейтинги вузов как имиджеформирующий компонент в аспекте формирования информационного пространства // Вестник Адыгейского государственного университета. Сер. 2: Филология и искусствоведение. 2018. № 2 (217). 